\title{
Glycol methacrylate-embedding medium to study morphological alterations of saphenous vein under brief and crescent pressurizations ${ }^{1}$
}

\author{
Inclusão em glicol metacrilato para estudar alterações morfológicas de veias safenas \\ humanas submetidas a pressurizações breves e crescentes
}

\author{
Cibele M. Prado ${ }^{\mathrm{I}}$, Fernanda Viaro" ${ }^{\mathrm{II}}$, Caroline F. Baldo ${ }^{\mathrm{III}}$, Viviane dos Santos Augusto ${ }^{\mathrm{IV}}$, Alfredo José Rodrigues ${ }^{\mathrm{V}}$, Paulo \\ Roberto Barbosa Evora ${ }^{\mathrm{VI}}$ \\ ${ }^{\mathrm{I}}$ Fellow PhD degree, Department of Pathology, Ribeirão Preto Faculty of Medicine, University of São Paulo, Brazil. \\ ${ }^{\text {II }}$ Fellow PhD degree, Department of Surgery and Anatomy, Ribeirão Preto Faculty of Medicine, University of São Paulo, Brazil. \\ III Fellow PhD degree, Department of Surgery and Anatomy, Ribeirão Preto Faculty of Medicine, Uiniversity of São Paulo, Brazil. \\ ${ }^{\text {IV }}$ Fellow Master degree, Department of Surgery and Anatomy, Ribeirão Preto Faculty of Medicine, University of São Paulo, Brazil. \\ v PhD, Professor, Division Thoracic and Cardiovascular Surgery, Department of Surgery and Anatomy, Ribeirão Preto Faculty of Medicine, \\ University of São Paulo, Brazil. \\ VI Full Professor and Head, Division Thoracic and Cardiovascular Surgery, Department of Surgery and Anatomy, Ribeirão Preto Faculty of \\ Medicine, University of São Paulo, Brazil.
}

\begin{abstract}
Purpose: This study sought to evaluate the efficiency of glycol methacrylate-embedding medium to detect morphological alterations of human saphenous vein submitted to brief and crescent pressurizations. Methods: Saphenous veins of 20 CABG patients were randomly distributed into four experimental groups (control, 100, 200 and $300 \mathrm{mmHg}$ pressures during 15 seconds). To quantify the percentage of endothelium spread over vein surface a microscope magnification of 100x was used for measurements. Morphometric analysis was performed using videomicroscopy with the Leica Qwin software in conjunction with a Leica microscope, videocamera, and an on-line computer. Results: A slight tendency of quantitative increase was observed in all parameters including percentage of endothelium spread over vein surface and thickness of saphenous vein walls (intima and media layers). Conclusions: The glycol methacrylate-embedding allowed sections with adequate resolution of structural details and revealed to be an extremely useful method to study pressurized human saphenous veins.
\end{abstract}

Key words: Saphenous Vein. Endothelium. Glycol Methacrylate-embedding Medium. High Resolution Light Microscopy.

\section{RESUMO}

Objetivo: Avaliar a inclusão em glicol metacrilato para estudar alterações morfológicas de veias safenas humanas submetidas a pressurizações breves e crescentes. Métodos: Veias safena de 20 pacientes submetidos a cirurgia de revascularização do miocárdio foram distribuídas ao acaso em quatro grupos experimentais (controle, pressões de 100,200 e $300 \mathrm{mmHg}$ durante 15 segundos). Para quantificar a percentagem da superfície venosa recoberta por endotélio utilizou-se o aumento de 100x. A análise morfométrica foi realizada utilizando-se videomicroscopia com auxílio do software Leica Qwin em conjunto com um microscópio Leica e videocâmera, acoplados a um computador. Resultados: Observou-se uma leve tendência de aumento quantitativo de todos os parâmetros avaliados, incluindo a percentagem de superfície recoberta por endotélio e a espessura das paredes das veias safenas. Conclusões: A inclusão em glicol metracrilato permitiu secções com adequada resolução dos detalhes estruturais, revelando-se um método extremamente útil para o estudo de veias safenas humanas pressurizadas.

Descritores: Veia Safena. Endotélio. Inclusão em Glicol Metacrilato. Microscopia Óptica de Alta Resolução.

1. Research performed at Department of Surgery and Anatomy and Department of Pathology, Ribeirão Preto Faculty of Medicine, University of São Paulo (USP), Brazil. 


\section{Introduction}

Saphenous vein is known to have worse patency than arterial grafts. ${ }^{1-3}$ This is partially related to the different structural and functional characteristics exhibited by normal saphenous vein which may be altered by high distention pressures performed during preparation or by insertion in arterial system itself. ${ }^{4,5}$ Studies comprising possible morphometric alterations of veins use paraffin embedding followed by conventional light microscopy. Paraffin embedding causes modification of tissue components, especially proteins, leading to considerable tissue shrinkage and loss of cytological detail. ${ }^{6,7}$ On this account, this study sought to evaluate the efficiency of glycol methacrylateembedding medium to detect morphological alterations of human saphenous vein under brief and crescent pressurizations.

\section{Methods}

Saphenous vein segments from the region near to the internal malleolus were harvested from 20 patients, irrespective of gender, submitted to coronary artery bypass grafting. The venous segments were gently released from surrounding tissue and their collateral branches were ligated. Subsequently, they were immediately immersed in a normothermic and oxygenated physiological solution with the following millimolar composition: $\mathrm{NaCl}, 118.3 ; \mathrm{KCl}, 4.7 ; \mathrm{MgSO}_{4}, 1.2 ; \mathrm{KH}_{2} \mathrm{PO}_{4}$, $1.22 ; \mathrm{CaCl}_{2}, 2.5 ; \mathrm{NaHCO}_{3}, 25.0$ and glucose, 11.1 (control solution). The veins were not submitted to distention with saline injection at the moment of harvesting. Veins without macroscopic evidence of varicosities were selected, but the diameter and wall thickness and macroscopic observation of vasospasms were not considered.

All the procedures were approved by the Research Ethics Committee of the Clinical Hospital, Ribeirão Preto Faculty of Medicine, University of São Paulo.

\section{Standardization of distention pressure}

To standardize the distention pressure, saphenous vein segments were connected to a threeway tap, with two outlets connected to a mercury manometer and to an insufflator used for balloon angioplasty. This insufflator allows a very accurate pressure increase during a period of time. As insufflations pressures are extremely high, the manometer of the insufflator is scaled in ATM and PSI. In this way, one outlet of the three-way tap was connected to a mercury column manometer to measure the experimental pressures $(100,200$ and $300 \mathrm{mmHg})$. In order to apply the three different levels of pressure, the free extremity of the vein segment was clamped (Figure 1). All preparations were performed by a single researcher. The vein segments were divided into four experimental groups: Group I - Control, Group II - Distention of $100 \mathrm{mmHg}$ during 15 seconds with Krebs solution, Group III - Distention of $200 \mathrm{mmHg}$ during 15 seconds with Krebs solution, and Group IV Distention of $300 \mathrm{mmHg}$ during 15 seconds with Krebs solution.

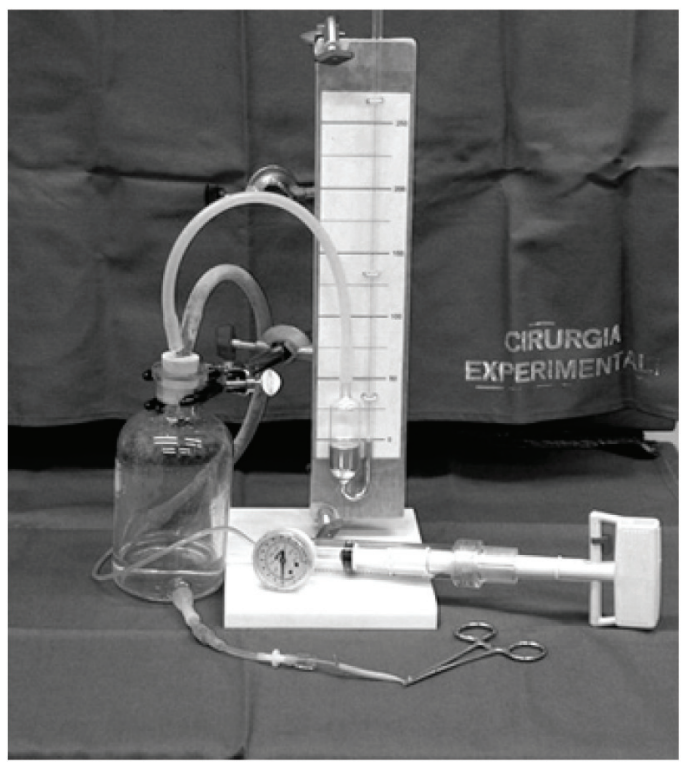

FIGURE 1 - Standardization of the pressure exerted on the saphenous veins.

\section{High resolution light microscopy}

The specimens were immersed in Karnovsky fixative and fixed overnight at $4^{\circ} \mathrm{C}$. Subsequently, they were dehydrated in 3 changes of graded ethanol 70, 95 and 100\%, for $20 \mathrm{~min}$ each. They were immersed in an infiltration solution: resin basic (Historesin ${ }^{\circledR}$ - Leica Instruments, GmbH, Heidelberg, Germany) and absolute ethanol (1:1) and resin basic alone for $24 \mathrm{~h}$ each. Afterwards, they were embedded in a resin basic and hardener mixture (15:1) in a polyethylene-embedding mold at room temperature. The blocks were left to polymerize for at least $24 \mathrm{~h}$. Sections 2.5 $\mu \mathrm{m}$ thick were cut with glass knives in an ultramicrotome and stretched on distilled water bath, mounted on uncoated glass slides and dried on a hot plate at $60^{\circ} \mathrm{C}$. They were stained with toluidine blue ${ }^{8}$ for $5 \mathrm{~min}$ and washed in running tap-water for $1 \mathrm{~min}$.

Morphometric analysis was performed using videomicroscopy with the Leica Qwin software (Leica Imaging Systems Ltd, Cambridge, England) in conjunction with a Leica microscope (Leica DMR, Leica Microsystems Wetzlar GmbH, Wetzlar, Germany), videocamera (Leica DC300F, Leica Microsystems AG, Heerbrugg, Switzerland), and an on-line computer.

To quantify the percentage of endothelium spread over vein surface a microscope magnification of $100 \mathrm{x}$ was used for measurements. The total internal perimeter of the vein and the percentage covered by endothelium were evaluated. Internal diameter was indirectly calculated by the following formula: $\mathrm{P}=\grave{\mathrm{A}} \cdot \mathrm{d}(\mathrm{P}=$ perimeter, $\grave{\mathrm{A}}=3.14$ and $\mathrm{d}=$ diameter). Thickness of the vessel wall (intima and media layers) was assessed using a microscope magnification of 
50x. A mean value was obtained from eight measurements which were distributed around the circumference of the vein. The frequency distribution of values was determined using a GraphPad Prism statistic program (GraphPad Software Inc., California, USA). Measurements were made by a skilled observer blinded to the experimental groups.

\section{Data Analysis}

Data were analyzed using a GraphPad Prism statistic program (GraphPad Software). For analysis, oneway analysis of variance (ANOVA) and the Bonferroni test (to correct for multiple comparisons) were used. A level of significance of $5 \%$ was chosen to denote the difference among group means. Data are presented as mean \pm standard error.

\section{Results}

Percentage of saphenous vein surface covered with endothelium obtained by high resolution light microscopy.

No significant differences were observed between control and the three levels of pressure. Figure 2 shows representative views of the experimental groups and the result of morphometric analysis.

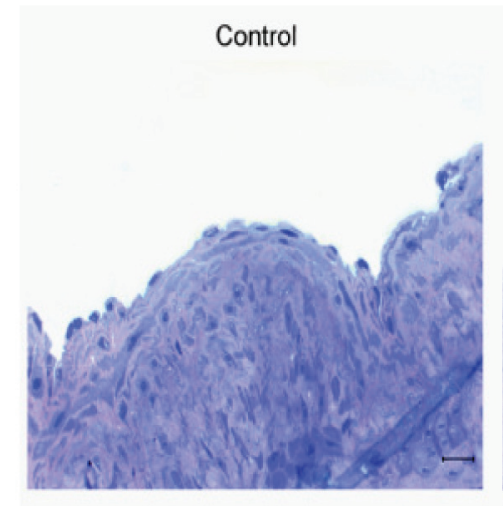

$200 \mathrm{mmHg}$
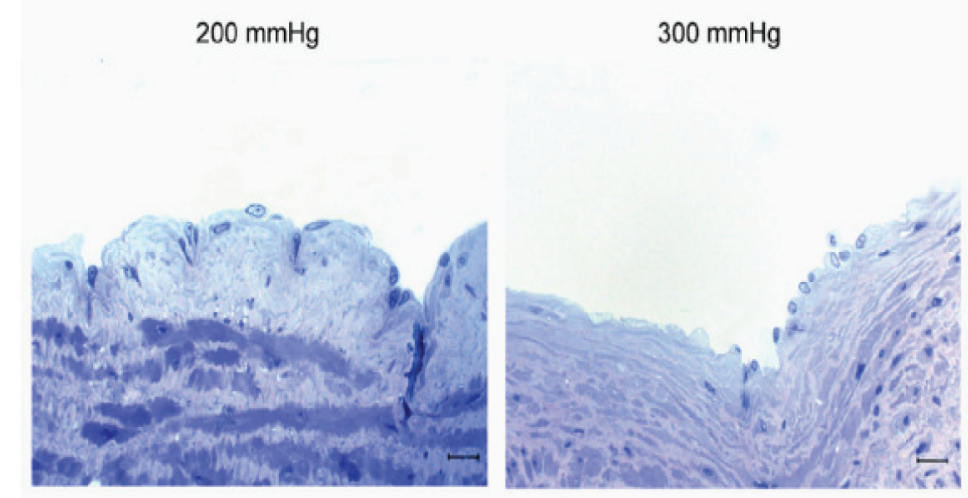

$100 \mathrm{mmHg}$

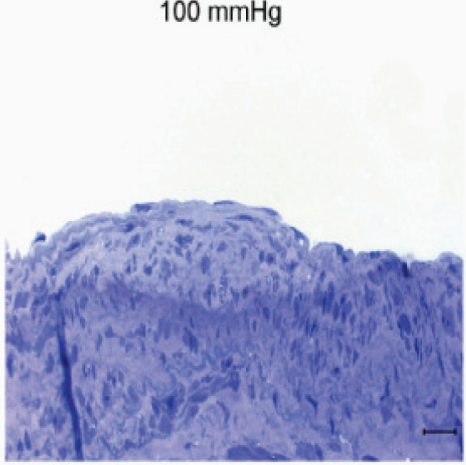
pressures 100, 200 and $300 \mathrm{mmHg}(400 \mathrm{x}$, bars $=20 \mu \mathrm{m})$. The graph shows the percent of intimal surface covered with endothelium $(n=20$; ANOVA and Bonferroni post test, $p>$ $0.05)$.

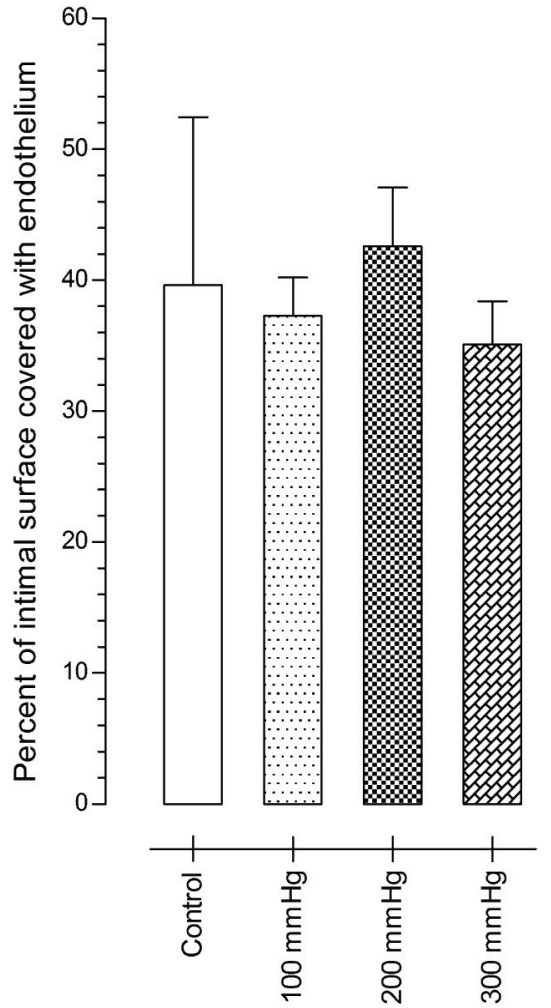

FIGURE 2 - High resolution light microscopy. Representative views of vein surface of control group and
Thickness of saphenous vein wall (intima and media layers)

No significant differences were observed between control and the three levels of pressure (Figure 3). When the percentile frequency distribution of saphenous vein thickness in the three experimental groups was plotted, it was quite similar to that observed in control (Figure 4). 


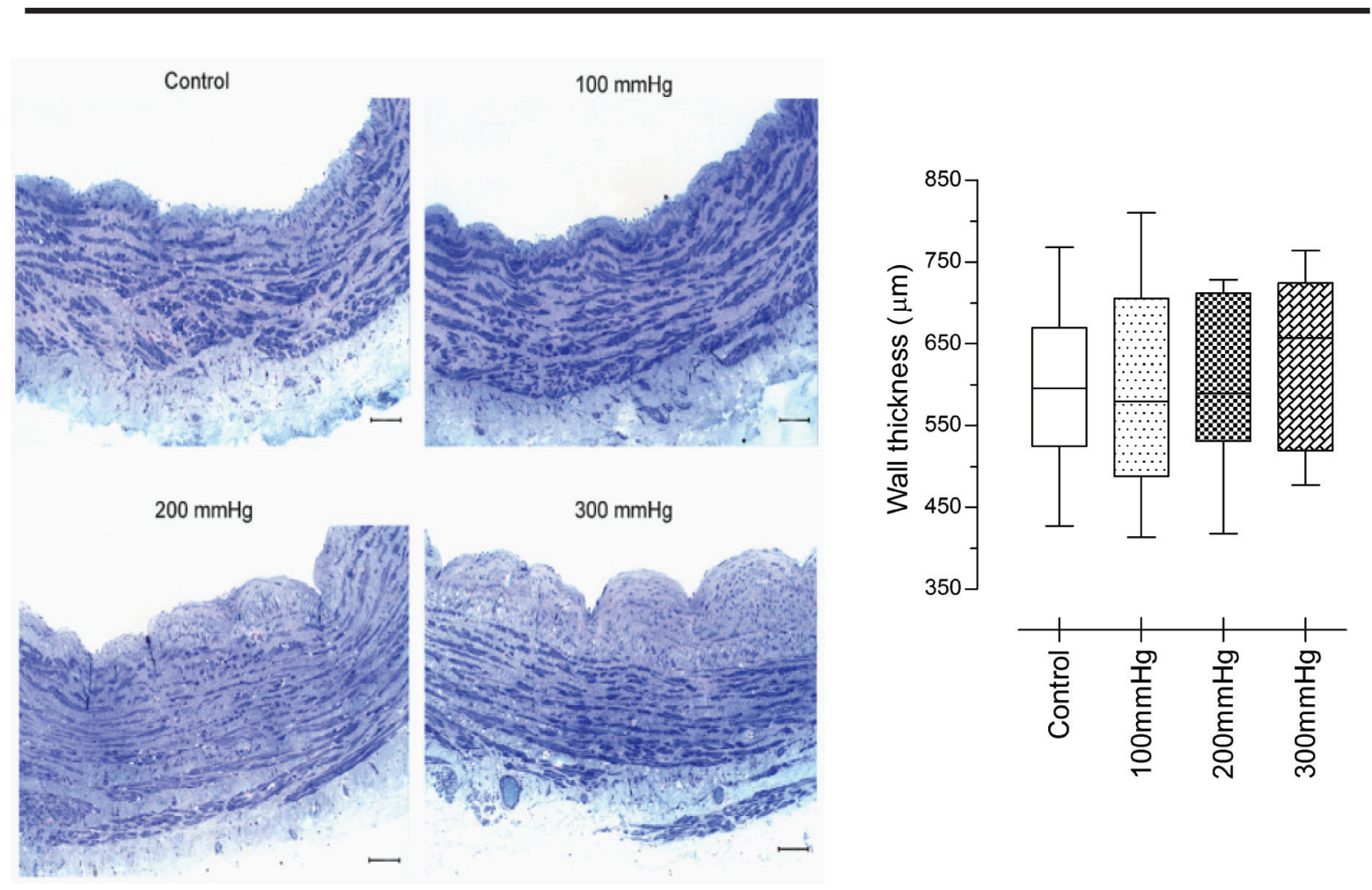

FIGURE 3 - High resolution light microscopy. Representative views of saphenous vein wall thickness (intima and media layers) in control group and pressures 100, 200 and $300 \mathrm{mmHg}(100 \mathrm{x}$, bars $=100 \mu \mathrm{m})$. The graph shows the wall thickness $(n=20$; ANOVA and Bonferroni post test, $\mathrm{p}>0.05$ ).

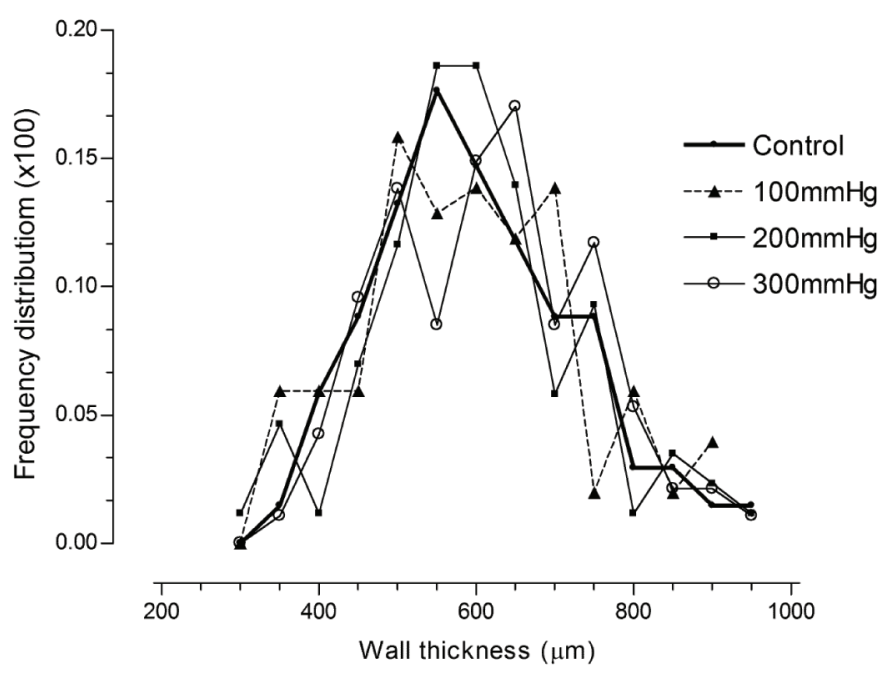

FIGURE 4 - Percentile frequency distribution of saphenous vein wall thickness in each group. 


\section{Perimeter of saphenous vein}

A clear tendency of greater perimeter in saphenous veins pressurized with $300 \mathrm{mmHg}$ was seen, but the differences among experimental groups were not statistically significant (Figure 5).

Perimeter

Control $\quad 3.83 \pm 0.62$

$100 \mathrm{mmHg} 3.67 \pm 0.32$

$200 \mathrm{mmHg} 4.08 \pm 0.62$

$300 \mathrm{mmHg} 5.59 \pm 0.70$

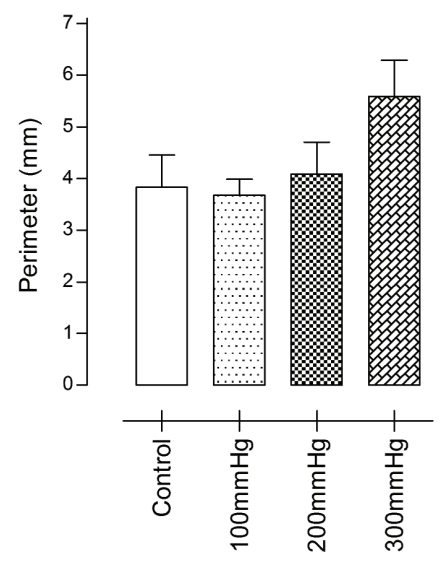

FIGURE 5 - Perimeter of saphenous vein in control group and pressures 100, 200 and 300 $\mathrm{mmHg}(\mathrm{n}=20$; ANOVA and Bonferroni post test, $\mathrm{p}>0.05)$.

\section{Internal diameter of saphenous vein}

Greater internal diameter was observed with increasing pressure, especially with $300 \mathrm{mmHg}$, but again, no statistical difference was observed between the experimental groups (Figure 6).

Internal diameter (mm)

Control $1.22 \pm 0.20$

$100 \mathrm{mmHg} 1.17 \pm 0.10$

$200 \mathrm{mmHg} 1.30 \pm 0.20$

$300 \mathrm{mmHg} 1.68 \pm 0.22$

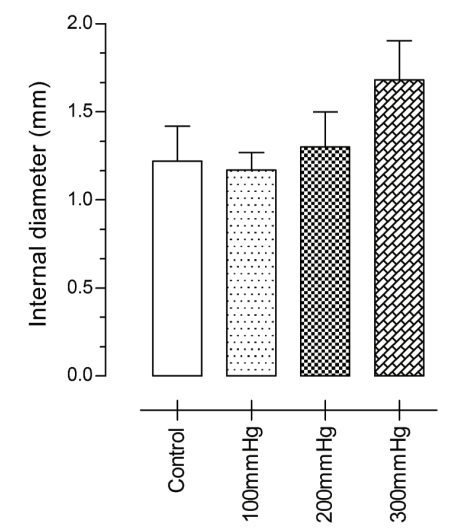

FIGURE 6 - Internal diameter of saphenous vein in control group and pressures 100, 200 and $300 \mathrm{mmHg}(\mathrm{n}=20$; ANOVA and Bonferroni post test, $\mathrm{p}>0.05)$.

\section{Discussion}

During 60 and 70 decades, it was clearly established that morphologic injuries not only occurred in the endothelium, but also in other layers composing the vein wall. There is an increasing necessity to characterize these morphologic alterations and there is no available methodology using light microscopy that enables the quantification of possible endothelial injuries with precision. In addition, the studies of vein endothelium are extremely difficult because of extreme feebleness and individual differences.

The use of scanning electron microscopy, originally proposed in this study, is complicated to be performed. It involves technical artifacts in relation to veins. This difficulty is mainly because the muscular layer: the vein must be opened longitudinally and residues must not be present. Because this, the final option was made for high resolution light microscopy.

Since the introduction of glycol methacrylate as an embedding medium in light microscopic research ${ }^{9,10}$, it has emerged as the best medium for light microscopy and become increasingly popular. A better morphological resolution than that of the traditional paraffin has been acquired and the use of glycol methacrylate avoid some technical artifacts that usually occur during histological procedures for paraffin embedding. ${ }^{11,12}$ The advantages that plastic embedding have towards conventional frozen and paraffin embedding media include good morphological preservation, thinner section cutting, high-quality section and it avoids technical artifacts. ${ }^{7,13,14}$ In this study, the use of plastic embedding allowed thin sections with adequate resolution of structural details for morphometric analysis.

A final commentary seems suitable. High resolution light microscopy did not demonstrate morphologic alterations of the endothelial layer in saphenous vein after pressurization $(100,200$ and $300 \mathrm{mmHg}$ ) as compared to control group. A previous study of our laboratory demonstrated endothelial dysfunction, characterized by the expression of CD34, a specific marker of endothelial dysfunction, after pressurization with $300 \mathrm{mmHg}$. The lack of statistical difference on percentage of endothelium spread over vein surface and on thickness of saphenous vein walls (intima a media layers) was completely unexpected when compared to this previous findings. A plausible speculation would be an early detection of endothelial dysfunction, characterized by expression of CD34, before morphologic alterations, characterized by high resolution light microscopy.

\section{References}

1. Zacharias A, Habib RH, Schwann TA, Riordan CJ, Durham SJ, Shah A. Improved survival with radial artery versus vein conduits in coronary bypass surgery with left internal thoracic artery to left anterior descending artery grafting. Circulation. 2004;109:1489-96.

2. Sabik III JF, Lytle BW, Blackstone EH, Houghtaling PL, Cosgrove DM. Comparison of saphenous vein and internal thoracic artery graft patency by coronary system. Ann Thorac Surg. 2005;79:54451.

3. Lajos TZ, Robicsek F, Thubrikar M, Urschel H. Improving patency of coronary conduits "valveless" veins and/or arterial grafts. J Card Surg. 2007;22:170-7.

4. Zócalo Y, Bia D, Pessana FM, Armentano RL. Changes in vein dynamics ranging from low to high pressure levels as a determinant of the differences in vein adaptation to arterial hemodynamic conditions. Artif Organs. 2007;31:575-80.

5. Bryan AJ, Angelini GD. The biology of saphenous vein graft occlusion: etiology and strategies for prevention. Curr Opin Cardiol. 1994;9:641-9. 
6. De Jonge HW, De Bakker MA, Verbeek FJ, Weijs WA. Embedding of large specimens in glycol methacrylate: prerequisites for multi-signal detection and high-resolution imaging. Microsc Res Tech. 2005;66:25-30.

7. Gerritz PO, Horobin R. Glycol methacrylate embedding for light microscopy: basic principles and trouble-shooting. J Histotechnol. 1996;19:297311.

8. Abreu MA, Baroza LGV, Rossi MA. Toluidine bluebasic fuchsin stain for glycolmethacrylate embedded tissue. The J Histotechnol. 1993;16:13940.

9 Ashley CA, Feder N. Glycol methacrylate in histopathology. A study of central necrosis of the liver using a water-miscible plastic as embedding medium. Arch Pathol. 1966;81:391-7.
10 Ruddell LC. Hydroxyethyl methacrylate combined with polyethylene glycol 400 and water; an embedding medium for routine $1-2 \mu \mathrm{m}$ sectioning. Stain Technol. 1967;42:119.

11 Woodruff JM, Greenfield SA. Advantages of glycol methacrylate embedding systems for light microscopy. The Journal of Histotechnology. 1979;2:164-7.

12 Hanstede JG, Gerritz PO. A new plastic for morphometric investigation of blood vessels, especially in large organs such as the human liver. Anat Rec. 1982;203:307-15.

13 Cerri PS, Sasso-Cerri E. Staining methods applied to glycol methacrylate embedded tissue sections. Micron. 2003;34:365-72.

14 Chapin RE, Ross MD, Lamb JC. Immersion fixation methods for glycol methacrylate-embedded testes. Toxicol Pathol. 1984;12:221-7.

\section{Acknowledgements}

To Mônica A. Abreu and Ligia G.V.B. Santoro for the excellent technical assistance.

To Professor Marcos A Rossi for his important suggestions and to make available the histology method.

FAPESP - Fundação de Amparo à Pesquisa do Estado de São Paulo and FAEPA - Fundação de Apoio ao Ensino, Pesquisa e Assistência do HCFMRP-USP.

\section{Correspondence:}

Paulo Roberto B. Evora

Rua Rui Barbosa, 367, Ap. 15

14015-120 Ribeirão Preto, SP, Brazil

Conflict of interest: none

Phone/Fax: (+55) 16 3602-2497

prbevora@netsite.com.br

\section{How to cite this article:}

Prado CM, Viaro F, Baldo CF, Augusto VS, Rodrigues AJ, Evora PRB. Glycol methacrylate-embedding medium to study morphological alterations of human saphenous vein under brief and crescent pressurizations. Acta Cir Bras [serial on the Internet], 2008; 23 Suppl 1. Available from URL: http://www.scielo.br/acb.

\section{Comments:}

The saphenous vein remains the most useful vein in coronary bypass surgery and a great number of studies were performed to characterize the morphological alterations that occur in different conditions. This study showed that the glycol methacrylate-embedding medium was efficient to produce a good morphological resolution without artifacts, but it did not detect the morphological alterations of human saphenous vein under brief and crescent pressurizations. The functional alterations probably occur before morphological alterations, as shown in other studies. The study considers a plausible speculation, which would be the early detection of endothelial dysfunction, characterized by expression of CD34, before morphological alterations, characterized by high resolution light microscopy. The authors chose to study histological alterations with high resolution light microscopy. It is an interesting study with appropriate methodology using morphometric analysis by video microscopy. However, it seems insufficient to detect molecular alterations and its consequences. Electron microscopy, as originally proposed, could possibly detect some morphological alterations. In any case, it was possible to verify that glycol methacrylate avoids the technical artifacts that usually occur during histological procedures with paraffin embedding. An alternative would be to study plastic and paraffin embedding in the same study and the same methodology.

\section{Edvaldo.Joviliano}

MD, PhD, Department of Surgery and Anatomy, Ribeirão Preto Faculty of Medicine, University of São Paulo, Brazil. 